\title{
Vôtke minust eesmärki! Monikielinen lapsi rakenteita yhdistämässä
}

\author{
HANNA JOKELA GEDA PAULSEN \\ Turun yliopisto Åbo Akademi
}

Tiivistelmä. Tutkimuksemme käsittelee erityisesti suomen kielen vaikutusta 10 -vuotiaan informanttimme viron kieleen kielen eri tasoilla. 10-vuotias informanttimme on kolmikielinen: hän puhuu äitinsä ja veljensä kanssa viroa ja isänsä kanssa norjaa; suomi toisaalta on keskeinen kieli koulun ja ystävien kielenä. Suomi ja viro ovat morfofonologisesti kompleksisia lähisukukieliä. Oletammekin, että rakenteeltaan läheiset kielet vaikuttavat kaksi- tai monikielisen puhujan kielenkäyttöön eri tavalla kuin rakenteeltaan toisistaan poikkeavat kielet. Toisaalta suomessa on viroa enemmän synteettisiä piirteitä, mikä saattaa näkyä myös informanttimme puhumassa virossa. Artikkelissa puhumme koodinvaihdon lisäksi koodien yhdistämisestä. Koodien yhdistämisellä tarkoitamme kahden kielen rakenteellista yhdistämistä samassa ilmauksessa. Koodien yhdistäminen ei edellytä tietoisen ja tiedostamattoman tiukkaa erottelua, joka on joissain tapauksissa - sekä lasten että aikuisten puheessa - mahdotonta. Suomen kielen vaikutusta voi löytää informantin virosta kielen kaikilla tasoilla. Suomen ja viron samankaltaisuudet antavat mahdollisuuksia koodien yhdistämiseen, mutta yksiselitteistä yhdistäminen ei ole. Koodien yhdistämiselle alttiita ovat etenkin rektiot ja konstruktiot. Informanttimme kielistrategiat ovat hyvin luovia ja monipuolisia.

Avainsanat: monikielisyys; koodien yhdistäminen; kielistrategiat; lähisukukieli; suomi; viro 


\section{Johdanto}

\subsection{Tavoitteet}

Artikkelin otsikko viittaa tutkimuskohteen monitahoisuuteen: aineistoesimerkkimme Võtke minust eesmärki on yhdistelmä viron kielen ilmaisusta Võtke minust eeskuju ja suomen ilmaisusta Ottakaa minusta mallia/esimerkkiä. Viron kielen sanan eeskuju informanttimme on todennäköisesti suomen kielen vaikutuksesta - korvannut sanalla eesmärk 'päämäärä.

Artikkelissa tarkastelemme kolmikielisen lapsen viron kieltä ja kielellisiä strategioita. Tutkimuskohteenamme on päivittäin viroa, suomea ja norjaa käyttävän 10-vuotiaan lapsen viron kieli ja siinä näkyvä - tietoinen ja tiedostamaton - suomen kielen vaikutus. Oletuksemme on, että rakenteeltaan läheiset kielet vaikuttavat kaksi- tai monikielisen puhujan kielenkäyttöön eri tavalla kuin rakenteeltaan toisistaan poikkeavat kielet. Tätä oletusta tukee Sirje Hassisen (2002) väitöskirjatutkimus, jossa tarkastellaan suomea ja viroa simultaanisti omaksuvien lasten kieltä. Tavoitteemme on selvittää morfofonologisesti kompleksisten lähisukukielten vaikutusta toisiinsa kolmikielisen lapsen kielessä kielen eri tasoilla. Tässä artikkelissa emme käsittele informanttimme kolmatta kieltä, norjaa.

Emme tarkastele varsinaista kielenomaksumisprosessia vaan jo kehittyneen kaksi- tai monikielisyyden piirteitä ja kommunikaatiostrategioita. Vasta kieltä omaksuvaan pikkulapseen verrattuna 10 -vuotias informanttimme on ilmeisen tietoinen käyttämistään kielistä sekä niiden yhdistelyn ja niillä leikittelyn mahdollisuuksista. Kehittyneestä kielitaidosta ja kielitietoisuudesta huolimatta suomen ja viron rinnakkaisessa käytössä saattaa olla hyvin läheisiä alueita, joiden vuoksi niissä näkyy myös tiedostamatonta vaikutusta toisiinsa. 


\subsection{Informantti ja aineisto}

Informanttimme Helen (nimi muutettu, kuten muutkin aineistossa esiintyvät nimet) on aineiston keräilyn aikana 10-vuotias. Hän on syntynyt Norjassa ja muuttanut 2-vuotiaana Suomeen; suomen kielen kanssa Helen on joutunut tiiviiseen kosketukseen jo päiväkodissa. Helen puhuu päivittäin kolmea kieltä: viroa, suomea ja norjaa. Äitinsä kanssa Helen puhuu viroa ja isänsä kanssa norjaa (vanhemmat keskenään käyttävät norjaa). Veljensä kanssa Helen puhuu viroa, joskin sisarustenvälisessä puheessa näkyy suomen kielen vaikutus erilaisilla kielen alueilla. Ennen suomen kielen omaksumista ${ }^{1}$ Helen on siis lähtökohtaisesti jo tutustunut kahteen kieleen perheen sisällä. Suomi ja samalla Turun murre on koulun ja ystävyyssuhteiden kieli, ja sillä on yhä merkittävämpi osa Helenin arjessa. Helenin kielistä norjan asema on selvästi heikoin, mitä osoittaa sekin, että paljon lukeva Helen lukee useimmiten suomeksi tai viroksi. Helen on vieraillut useammin Virossa kuin Norjassa. Koulussa Helen on osallistunut kotikielen (viron) opetukseen luokilla 1.-5. Helen pyrkii aktiivisesti käyttämään ja soveltamaan itse koulussa, harrastuksissa sekä kavereilta kuultua sekä kirjoista, sarjakuvista ja lehdistä luettua. Helenin puheessa kuuluu myös vieraiden kielten (saksan ja englannin) oppitunneilla opittu; hän pyrkii käyttämään ja kokeilemaan opittuja ilmauksia tai sanoja vapaassa keskustelussa.

Artikkelimme aineisto perustuu vuonna 2008 noin kuuden kuukauden aikana tekemiimme havaintoihin sekä nauhoitukseen, jonka pituus on 75 minuuttia. Nauhoituksessa on mukana kolme henkilöä: tämän artikkelin tekijät sekä Helen. Muu aineisto on kerätty keskusteluissa, joissa on ollut mukana joko Paulsen ja Helen tai (harvemmin) Jokela ja Helen tai kaikki kolme. Keskustelujen kieli on pääsääntöisesti viro. Joissain keskustelutilanteissa mukana on Helenin isoveli. Jokelan äidinkieli

\footnotetext{
1 Emme ota tässä kantaa siihen, onko Helenin suomen kieli omaksuttu simultaanisena vai suksessiivisena. Kysymys kielen omaksumisen ja oppimisen kannalta kriittisestä iästä on herättänyt paljon keskustelua; kriittisen iän ajoittumisesta ei ole yksimielisyyttä, ja toiset tutkijat ovat kyseenalaistaneet kriittisen iän hypoteesin kokonaan (ks. Ellis 1994: 484-492).
} 
on suomi, ja hän hallitsee hyvin viron kielen; Paulsen puolestaan puhuu viroa äidinkielenään ja hallitsee hyvin suomen kielen. Tämä lähtökohta todennäköisesti vaikuttaa Helenin keskusteluissa tekemiin valintoihin, koska hän tietää osanottajien ymmärtävän hyvin molempia kieliä. Lasten sosiolingvististen taitojen omaksuminen on kiinnostava tutkimuskohde; tutkimuksissa on huomattu jopa kolmivuotiaiden lasten mukauttavan puhettaan kuulijoiden mukaan (ks. esim. Korpela 2002: 5).

\section{Kaksi- tai monikielisyys ja kielten vaikutus toisiinsa}

Vivian Cook (2003: 10) painottaa, että kaksikielisellä puhujalla molemmat kielet vaikuttavat koko ajan toisiinsa. Kahden tai useamman kielen omaksumista ja oppimista käsittelevissä tutkimuksissa kuvataan koodinvaihtoa, lainaamista, koodien yhdistymistä ja interferenssiä. Termejä on käytetty sekä kaksikielisyys- että kielikontaktitutkimuksissa, ja niitä käytetään osittain päällekkäin.

Gumperz (1982: 66) määrittelee koodinvaihdon kielellisen aineksen prosessoinniksi, jossa operoi kaksi erillistä kieliopillista systeemiä. Magdalena Kovács (2009: 24) käyttää koodinvaihtoa yläkäsitteenä; tällöin koodinvaihto kattaa kahden tai useamman kielen tai koodin esiintymisen saman keskustelun aikana. Koodinvaihdon voi nähdä olevan lähellä lainaamista. Vanhat lainat ovat jo osa uuteen kieleen vakiintunutta sanastoa, sen sijaan niin sanotut tilapäislainat ja koodinvaihto on yksittäisessä keskustelutilanteessa vaikea erottaa toisistaan (Kovács 2009: 24-25). Vakiintuneisuus on siis juuri lainojen keskeinen piirre; toisaalta Kovács (2009: 25) ei pidä lainojen ja koodinvaihdossa käytettyjen yksittäisten sanojen erottamista toisistaan aina relevanttinakaan.

Suomen ja viron simultaanista omaksumista ja niiden keskinäistä vaikutusta kahden pienen lapsen kielessä on tarkastellut Hassinen (2002). Koska Hassisen tutkimuskohde on pienten lasten kieli, hän ei työssään käsittele koodinvaihtoa tai lainaamista, vaan tarkastelee koodien yhdistymistä. Psykologiselta kannalta koodien yhdistyminen on tiedostamatonta, kun taas koodinvaihto edellyttää Hassisen mukaan 
(2002: 46) tietoisuutta kaksikielisyydestä ja puhetilanteesta. Marilyn M. Vihmanin (1985: 317) mukaan koodinvaihdon ilmaantuminen kaksikielisen lapsen puheeseen edellyttää metalingvististä ja pragmaattista kehittyneisyyttä. On esitetty, että kaksikielisyys vaikuttaa myönteisesti metalingvistiseen tietoisuuteen (kokoavasti viimeaikaisia tutkimuksia esittelee Baker 2006: 156-158). Suomessa asuvien aikuisten virolaisten kaksikielisyyttä ja koodinkopiointia (koodikopeerimine) tutkii väitöskirjassaan Kristiina Praakli (2009).

Tässä artikkelissa käytämme termejä koodinvaihto ja koodien yhdistäminen. Koodien yhdistämisellä tarkoitamme kahden kielen rakenteellista yhdistämistä samassa ilmauksessa. Termi on neutraalimpi kuin koodien sekoittaminen ja toisenlainen kuin pienen lapsen kieleen liitetty koodien yhdistyminen, sillä yhdistäminen edellyttää aktiivisempaa toimijaa. Termi ei edellytä tietoisen ja tiedostamattoman tiukkaa erottelua, joka on joissain tapauksissa - sekä lasten että aikuisten puheessa - mahdotonta.

Timo Lauttamuksen (1990: 8) mukaan sekä koodinvaihto- että lainaamisprosessien tuloksia voidaan tarkastella ja luokitella esimerkiksi pragmaattisesti (koodinvaihto kommunikaatiostrategiana), psykolingvistisesti, sosiolingvistisesti ja myös kielen rakenteen kannalta. Aikuisten viro-suomi-kaksikielisyyttä tarkastellut Kristiina Praakli (2008: 170) huomauttaa, että hänen aineistossaan koodinvaihdolla on selvästi kommunikatiivisia tehtäviä. Meidän aineistossamme koodinvaihto on ennen kaikkea kommunikaatiostrategia ja kuuluu pragmatiikan ilmiöihin ja koodien yhdistäminen on puolestaan lähtöisin rakenteellisista tekijöistä. Arvioimme, että informanttimme yhdistelee kieliä sekä tietoisesti että tiedostamatta.

Hassinen (2002: 184) toteaa, että viron ja suomen kaksikielisyydessä saattaa kielten läheisyys joillakin alueilla nopeuttaa ja joillakin hidastaa kielten eriytymistä. Hassinen analysoi suomen ja viron omaksumista kielten ominaispiirteiden mukaan kolmessa ryhmässä: täysin identtiset, osittain päällekkäiset ja täysin erilaiset piirteet. Samankaltaisia ja eroavia piirteitä Hassinen on löytänyt kielen kaikilta tasoilta. (Hassinen 
2002: 185.) Hassisen käyttämä piirteiden luokittelu sopinee myös varttuneemman lapsen kielen tarkasteluun. Hassisen tutkimuksen perusteella näyttää siltä, että täysin identtiset ja täysin erilaiset piirteet pystytään erottamaan, mutta kielten päällekkäisyydet ja funktionaaliset erot, aiheuttavat koodien yhdistymistä (Hassinen 2002: 188).

Helka Riionheimo (2007) tarkastelee väitöstutkimuksessaan kielikontaktiteorian näkökulmasta inkerinsuomea, johon vaikuttaa voimakkaasti viron kieli. Riionheimo (2007: 255) korostaa, että kahden läheisen sukukielen kontaktissa kieltenvälinen vaikutus on hyvin laajaa ja monimuotoista. Vaikka oma tutkimuksemme ei olekaan kielikontaktitutkimus, tästäkin aineistosta nousee esiin ilmiön kompleksisuus - aina ei ole mahdollista löytää yksiselitteistä mallia koodien yhdistämisen taustalla olevista prosesseista.

\section{3. Äännetason ilmiöitä}

Kuten muillakin kielen alueilla, viron ja suomen fonologiassa on sekä yhteisiä, osittain päällekkäisiä että erilaisia piirteitä. Yleisesti ottaen kummankaan kielen erikoisuudet, kuten esimerkiksi viron palatalisaatio ja /õ/ tai suomen rajageminaatio (ISK: 66) eivät aiheuta vaikeuksia ja pysyvät Helenin kielessä erossa. Helenin kielessä on huomattavissa joitakin koodien yhdistämisilmiöitä alueilla, jotka ovat osittain päällekkäiset. Molemmissa kielissä sanan pääpaino on yleensä ensimmäisellä tavulla, suomessa kuitenkin viroa useammin myös vierasperäisissä sanoissa. Joissakin tapauksissa Helen saattaa kallistua suomenkieliseen painotukseen vironkielisessäkin puheessa. Esimerkissä (1) sanan sümmetriline Helen ääntää ensimmäistä tavua painottaen, viroksi paino olisi toisella tavulla /süm'meetriline/.

(1) See puutöö õpetaja arvioi selle perusteella, et see laev, mis me tegime, kas see oli sümmetriline /'sümmetriline/ või mitte.

'Se puutyön opettaja arvioi sillä perusteella, että se laiva jota me teimme, oliko se symmetrinen tai ei.' 
Esimerkissä (1) on muitakin suomen kielen vaikutukseen viittaavia piirteitä, kuten verbilekseemivalinta arvioida 'hinnata' ja märite perusteella 'põhjal'. Myöhemmin samassa keskustelussa kuitenkin vakiintuu viron sääntöjen mukainen ääntämys, ja sanan sümmeetriline paino on viron kielen mukainen. Lauseessa (2) ei ole lainkaan suomen kielen vaikutusta:

(2) Ja muidu ka see puutöö õpetaja on nii... sümmeetriline /süm'meetriline/.

'Ja muutenkin tämä puutyön opettaja on niin... symmetrinen'.

Suomessa klusiilit $g, b$ ja $d$ ovat soinnillisia (joskin ääntämyksessä on yksilöllistä ja alueellista vaihtelua), virossa ne äännetään lähinnä foneemien / $\mathrm{k}, \mathrm{p}, \mathrm{t} / \mathrm{n}$ lyhyinä äänivariantteina soinnillisessa ympäristössä (EKK: 57). Helenin ääntämyksessä nämä klusiilit saattavat esiintyä soinnillisina, jos viron sana on samanasuinen suomen kanssa. Tällainen on esimerkiksi viron sana banaan, jonka $b$ ääntyy Helenillä kuten suomen banaani-sanassa.

Suomen vokaaliharmonialla on vaikutusta Helenin ilmauksiin, jos suomen kielen sana on yhdistetty vironkieliseen kontekstiin. Esimerkissä (3) verbin lähetama vartalo on muodoltaan läheinen suomen lähettää-verbin kanssa. Merkille pantavaa on, että Helen käyttää vokaaliharmoniaa muuten morfologisesti virolaisessa sanassa. Mahdollinen selitys tälle on, että Helen ei heti muista saatma-verbiä, joka olisi idiomaattisempi vaihtoehto lauseen merkitystä ajatellen.

(3) Misasja, ega sa midagi ei lähetänüd [lähetanud]?

'Mitä, ethän lähettänyt mitään?'

Kirjainten nimityksiä Helen ääntää yleensä suomalaisittain, kuten esimerkissä (4). Suomalaisittain Helenillä ääntyvät myös vieraiden kielten sanat, esimerkiksi heavy ääntyy /heavü/.

(4) Tulime tagasi sellise väiksega, sellise /äm äs/ [em es] Ruissaloga. 'Palasimme sellaisella pienellä, sellaisella M/S Ruissalolla.' 


\section{Morfologisia piirteitä}

Millaisia mahdollisuuksia suomen ja viron morfologian samankaltaisuus antaa koodien yhdistämiseen? Kai Stahl (2002) on tarkastellut 10ja 14-vuotiaiden Suomessa asuvien virolaispoikien viroa suomen kielen vaikutuksen kannalta. Stahlilla on runsaasti havaintoja vironkielisten sijapäätteiden liittämisestä suomenkielisiin sanavartaloihin. Stahl (2002: 124) huomauttaa, että virolaisten päätteiden lisääminen on sujuvaa juuri kielten samankaltaisuuden takia.

Virolaisten päätteiden ja suomalaisten sanavartaloiden yhdistämistä Helenin kielessä on kuitenkin varsin vähän. Onko tämä piirre idiolektilähtöinen? Käyttäessään virolaisessa lauseessa suomenkielistä sanaa hän yleensä säilyttää sanassa suomen kielen morfologian. Esimerkissä (5) suomen kielen kalju-sanaan liittyy suomalainen komparatiivi -mpi, esimerkissä (6) on täysin suomenkielinen passiivimuoto.

(5) Ta peaks natuke kaljumpi [kiilam] olema.

'Hänen pitäisi olla vähän kaljumpi.'

(6) Suomen Joutsen, seda kunnostettiin [remonditi] nagu ---.

'Suomen Joutsen, sitä kunnostettiin kuin ---'.

Esimerkiksi aste- ja äännevaihtelut ovat tekijöitä, jotka estävät osaltaan suomenkielisen sanavartalon ja virolaisen päätteen yhdistämisen Helenin kielessä. Esimerkissä (7) esiintyy monikon partitiivi pysähdyksiä. Nykyvirossa ei ole $-V s>-k s e$-vaihtelua (sm. varis: variksen; ee. vares: varese), minkä vuoksi kahdesta kielestä yhdistetty muoto tuntunee suomen äännevaihtelun hallitsevasta Helenistä hankalalta.

(7) Miks see teeb selliseid pysähdyksiä [peatusi]?

'Miksi se tekee sellaisia pysähdyksiä?'

Aineistostamme löytyy myös esiintymä (esimerkki 8), jossa Helen on yhdistänyt suomalaiseen verbiin viron kielen yksikön 3. persoonan päätteen $-b$. Tässä tilanteessa Helen vaikutti selvästi tietoiselta siitä, että kiristää-verbi on suomea, mutta se tuli hänen mieleensä helpommin ja 
yksisanaisena se on myös yksinkertaisempi kuin vironkielinen fraasiverbi välja pressida.

(8) Pongo kiristäb [pressib välja] mind.

'Pongo kiristää minua'

Verbien valinnassa suomen kielen synteettisyys näyttää vaikuttavan Helenin kielellisiin ratkaisuihin. Suomen kieli on synteettisempää kuin viro, ja viron kielessä esimerkiksi fraasiverbit ovat tavallisempia kuin suomessa. Vaikuttaa siltä, että Helen valitsee usein suomalaisen verbin silloin, kun virossa käytettäisiin fraasiverbiä. Myös Stahlin (2002) informanttien virolaisessa puheessa esiintyy suomalaisen kaltaisia, yhden sanan synteettisiä ilmauksia virolaisen fraasiverbin asemesta, esimerkiksi: Nad kostavad sulle (vir. Nad maksavad sulle kätte, sm. He kostavat sinulle). Stahl (2002: 125) arvelee, että suomenkielisen verbin käyttäminen saattaa informantin mielestä tuntua kätevämmältä ratkaisulta, koska se on lyhyempi kuin viron kielen ilmaisutapa.

\section{Syntaktisia piirteitä}

Predikatiivi voi esiintyä nominatiivissa, partitiivissa tai genetiivissä sekä suomessa että virossa. Suomen kopulalauseessa predikatiivi on useammin partitiivissa kuin viron kopulalauseessa. Esimerkissä (9) Helen yhdistääkin suomen mallin mukaisesti partitiivimuotoisen predikatiivin virolaiseen kopulalauseeseen. Virossa subjektitarkoitteen koostumusta ilmaiseva ainesana hõbe ei kuitenkaan olisi partitiivissa vaan elatiivissa.

(9) Need kõrvarõngad on hõbedat [hõbedast].

'Nämä korvakorut ovat hopeaa.'

Esimerkissä (10) Helen yhdistää viron nominatiivipredikatiivin suomen olla väärässä -rakenteeseen, jonka vaikutuksesta viron sana vale on inessiivissä.

(10) Bussikellad on alati vales [valed].

'Bussin kellot ovat aina väärässä' 
Tyypillisimpiä viron ja suomen kaksikielisyyden ilmiöitä lienevät verbien rektioiden poikkeamat. Esimerkeissä (11) ja (12) näkyy myös suomen synteettisyyden vaikutus. Virolaisen adpositiolausekkeen asemesta Helen käyttää pelkkää sijapäätettä.

(11) Tänan pörriäisest [pörriäise eest]!

'Kiitän pörriäisestä!'

(12) Ronisin puusse [puu otsa].

'Kiipesin puuhun.'

Aikailmaukset näyttävät olevan haasteellisia rakenteita, jotka aiheuttavat pohtimista. Helen on sisäistänyt suomen kellonaikarakenteet, joissa sanajärjestys on päinvastainen kuin virossa (esimerkki 13). Vaikuttaa siltä, että Helen on yleistänyt nominatiivin käytön kellonaikojen ilmaisuun silloinkin, kun virossa ja suomessa pitäisi molemmissa käyttää genetiiviä (esimerkki 14). Emme usko, että Helen jättää lukusanan nominatiiviin välttääkseen taivuttamista, sillä hänen kielensä kokonaisuudessaan on morfologisesti rikasta.

(13) Kell on kümme üle kolm [kolm läbi kümme (minutit)].

'Kello on kymmenen yli kolme.'

(14) Lähen umbes kakskümmend [kahekümne] minuti pärast.

'Lähden noin kahdenkymmenen minuutin päästä.'

Myös järjestyslukuilmauksissa voi havaita suomen ja viron rakenteiden yhdistämistä. Esimerkissä (15) on molemmissa kielissä kompleksinen rakenne, jonka pohjana on suomen konstruktio yhdistettynä viron lekseemeihin ja morfologiaan.

(15) --- teiseks parim [paremuselt teine] ---.

'--- toiseksi paras ---' 


\section{Sanastosta}

Kouluun liittyvä sanasto on Helenille luonnollisesti tutumpaa suomeksi kuin viroksi, ja koulusta puhuttaessa puheessa esiintyy selvää koodinvaihtoa, kuten esimerkissä (16) luokkaretkellä.

(16) Me olime luokkaretkellä Ruissalos, käisime ---.

'Me olimme luokkaretkellä Ruissalossa, kävimme ---'

Esimerkissä (17) Helen kuvailee opettajaa ja käyttää suomenkielistä ilmausta oppilaiden keskuudessa, joka vaikuttaa varsin muodolliselta mutta johon sisältynee esimerkiksi nuortenkirjojen tyylistä ironiaa. Tällaisessa tapauksessa on helppo yhtyä Gumperzin (1982: 72) näkemykseen, jonka mukaan koodinvaihto ei ole satunnaista, vaan siihen motivoivat todennäköisemmin tyylilliset kuin kieliopilliset tekijät.

(17) Tema nimi on Mätä Perttinen, tegelt Pertti Perttinen, aga oppilaiden keskuudessa Pertti Mätä Perttinen.

'Hänen nimensä on Mätä Perttinen, oikeastaan Pertti Perttinen, mutta oppilaiden keskuudessa Pertti Mätä Perttinen.'

Helenin koodien yhdistäminen voi olla hyvin luovaa. Suomen läikkä ja viron laik yhdistyvät esimerkissä (18). Tässä esimerkissä on huomattavan paljon taukoja, mikä osoittaa epävarmuutta ja oikean sanan hakemista.

(18) Siin on selline... tukk... sellised juuksed ja siis siin on mingi alustassisuurune selline ilma juusteta läik.

'Tässä on sellainen... tukka... sellaiset hiukset ja sitten siellä on joku aluslautasen kokoinen hiukseton läikkä/laikku.'

Luovaa koodien yhdistämistä esiintyy myös esimerkissä (19), jossa närkästynyt Helen moittii veljeään. Suomen kielen nostaa meteli -idiomi on siirretty viroon: nostaa-verbi on käännetty viron tõsta-verbillä ja viron kieleen kuulumaton sana meteli on otettu sellaisenaan ilmaukseen.

(19) Pongo, sa tõstad meteli [tõstad kisa] ${ }^{2}$ sellest kui ma sinust mööda lähen! 'Pongo, sinä nostat metelin siitä, kun kuljen sinun ohitsesi!'

2 Vironkielinen vastaava ilmaus, joka ilmeisesti on Helenille tuntematon. 


\section{Lopuksi}

Suomen kielen vaikutusta voi löytää Helenin virosta kielen eri tasoilla. Suomen ja viron morfologian samankaltaisuudet antavat mahdollisuuksia koodien yhdistämiseen, mutta toisaalta rajoituksiakin on. Lähisukukielten rakenteelliset erot näkyvät Helenin virossa. Koodien yhdistämiselle alttiita ovat etenkin rektiot ja konstruktiot.

Hassisen (2002) perusteellisen suomi-viro-kaksikielisyystutkimuksen vertauskohteeksi tarvitaan mielestämme myös isompien lasten kaksikielisyystutkimusta. Tutkimuksemme täydentääkin tätä kuvaa. 10 -vuotias on sosiaalisesti ja kielellisesti kiinnostavassa vaiheessa, jossa taidot ja tiedot karttuvat ja ympäristön vaikutus on suuri. Tällä kaikella on vaikutusta kielellisiin strategioihin. Aiomme jatkaa Helenin kielen tarkastelua, ja olemme kiinnostuneita etenkin koodien yhdistämisestä konstruktioissa ja syntaksin tasolla.

Helen käyttää koodinvaihtoa ns. kaksikielisissä tilanteissa, joissa hän tietää muidenkin osallistujien hallitsevan sekä suomea että viroa. Koodinvaihto ei ole seurausta yksinomaan kaksi- tai monikielisyydestä, vaan siihen motivoivat myös tyylilliset ja tilannesidonnaiset seikat. Konteksti, jossa ilmaus on kuultu, vaikuttaa kielelliseen rakenteeseen. Helenin kielistrategiat ovat hyvin kompleksiset, ja hän käyttää kaikkia kieliresurssejaan luovasti.

\section{Kiitokset}

Kiitämme artikkelin tuntemattomia arvioijia hyödyllisistä kommenteista. Olemme esitelleet tutkimuskysymyksiämme myös Virsu-seminaarissa Seilissä 2008, Turun yliopiston suomen kielen tutkijaseminaarin artikkelikurssilla 2009 sekä Åbo Akademin kieliaineiden Spremi-seminaarissa 2009. Olemme kiitollisia kaikille keskusteluihin osallistuneille. Vastuu tässä artikkelissa esitetyistä väitteistä kuuluu kuitenkin luonnollisesti meille. 


\section{Lähteet}

Baker, Colin 2006. Foundations of Bilingual Education and Bilingualism. Fourth edition. Bilingual Education and Bilingualism 54. Clevedon: Multilingual Matters Ltd.

Cook, Vivian 2003. Introduction: the changing L1 in L2 user's mind. - Vivian Cook (Ed.). Effects of the second language on the first. Second Language Acquisition 3. Clevedon: Multilingual Matters Ltd, 1-18.

Ellis, Rod 1994. The Study of Second Language Acquisition. Oxford: Oxford University Press.

EKK $=$ Erelt, Mati, Tiiu Erelt, Kristiina Ross 2007. Eesti keele käsiraamat Tallinn: Eesti Keele Sihtasutus.

Gumperz, John 1982. Discourse Strategies. Cambridge: Cambridge University Press.

Hassinen, Sirje 2002. Simultaaninen kaksikielisyys. Läheiset sukukielet suomi ja viro rinnakkain. Acta Universitatis Ouluensis. B, Humaniora 43. Oulu: Oulun yliopisto.

Korpela, Eveliina 2002. Lapset lääkäreinä ja potilaina: Miten institutionaalisia rooleja ilmaistaan leikeissä? - Virittäjä 106, 2-34

Kovács, Magdalena 2009. Koodinvaihto ja kielioppi. - Jyrki Kalliokoski, Lari Kotilainen, Päivi Pahta (Toim.). Kielet kohtaavat. Helsinki: Suomen Kielen Seura.

ISK = Hakulinen, Auli, Marja Vilkuna, Riitta Korhonen, Vesa Koivisto, Tarja Riitta Heinonen, Irja Alho 2004. Iso suomen kielioppi. Suomalaisen Kirjallisuuden Seuran toimituksia 950. Helsinki: Suomalaisen Kirjallisuuden Seura.

Lauttamus, Timo 1992. Lainaaminen ja koodinvaihto: havaintoja amerikansuomalaisten kielestä. - Virittäjä 96, 3-17.

Praakli, Kristiina 2008. Eestlased ja eesti keel Soomes. - Helle Metslang, Riho Grünthal (Toim.). Lähivertailuja 18. Uralica Helsingiensia 1. Helsinki: Helsingin yliopiston suomalais-ugrilainen laitos, 158-176.

Praakli, Kristiina 2009. Esimese põlvkonna Soome eestlaste kakskeelne keelekasutus ja koodikopeerimine. Dissertationes philologiae Estonicae Universitatis Tartuensis 24. Tartu: Tartu Ülikooli Kirjastus.

Stahl, Kai 2002. Suomen kielen vaikutusta kahden Suomessa asuvan virolaislapsen äidinkielisessä puheessa. - Maija Järvenpää, Kirsti Siitonen (Toim.). Matkalla toiseen kieleen: viisi praktikumtyötä äidinkielen ja opittavan kielen siirtovaikutuksista. Turun yliopiston suomalaisen ja yleisen kielitieteen laitos. Turku: Turun yliopisto, 117-133.

Vihman, Marylin 1985. Language differentiation by the bilingual infant. - Journal of Child Language 12, 297-324. 


\title{
Võtke minust eesmärki! Structure combining of a multilingual child
}

\author{
HANNA JOKELA \\ GEDA PAULSEN \\ University of Turku \\ Åbo Akademi University
}

Our aim is to discuss language strategies of a trilingual child, who uses Estonian, Finnish and Norwegian on a daily basis. Especially, we focus on the influence of the Finnish language on the Estonian language used by our informant. Estonian and Finnish are closely related languages, and they both have rich morphological system. We argue that the interaction between morphologically rich inflectional systems is different than the interaction between morphologically very different systems.

Our informant speaks Estonian with her mother and brother and Norwegian with her father. She lives in Finland, and Finnish is her school language as well as the language of many daily situations. At the time of collecting the data, she was 10 years old.

Hassinen (2002) has studied younger Estonian-Finnish bilingual children and their language mixing. Hassinen demonstrates that the closeness of the two languages may in Finnish-Estonian bilingualism in some areas facilitate and in other decelerate the differentiating of two languages.

The notions language mixing and code emerging stand for unconscious processes, and they are typical for small children. However, our 10-year old informant has remarkably higher linguistic awareness, and different possibilities for applying complex strategies than small children have. We focus on code switching and code combining. In this study, code switching is seen as a communicative strategy; typically, the stylistic and pragmatic characteristics of languages used in a multilingual situation are utilized. By code combining, we mean combining of structural elements of two languages within one linguistic expression. The linguistic processing behind code combining may be conscious or unconscious. We argue that code combining is a typical process in closely related, inflectionally similar languages, such as Finnish and Estonian. The code 
combining is applied in phonological, morphological and syntactic levels of our informant's language.

Keywords: multilingualism; code combining; language strategies; closely related languages; Finnish; Estonian

\section{Hanna Jokela}

Suomen kieli

20014 Turun yliopisto, Finland

hakajo@utu.fi

\section{Geda Paulsen}

Finska språket

Fabriksgatan 2

20500 Åbo, Finland

gpaulsen@abo.fi 